\title{
ИССЛЕДОВАНИЕ ПЕРИОДИЧНОСТИ ЗАМЕНЫ МОТОРНОГО МАСЛА НА ДИЗЕЛЬНЫХ АВТОМОБИЛЯХ
}

\author{
Б.С. Антропов (фото) \\ д.т.Н., профессор, профессор кафедры автомобильного \\ транспорта \\ ФГБОУ ВО «Ярославский государственный технический \\ университет», г. Ярославль
}

В.В. Гуменный

доцент кафедры тактики и общевоенных дисциплин

В.А. Генералов

преподаватель кафедры тактики и общевоенных дисциплин Ярославское высшее военное училище противовоздушной обороны, г. Ярославль

В Российской Федерации до настоящего времени действует система технического обслуживания автомобилей отечественного произ-

Техническое

обслужнвание (ТO), неблагоприятные условия эксплуатации, рекомендуемое моторное масло, поправочный коэффициент, грузоподъёмность, периодичность замень

Maintenance, adverse operating conditions, recommended engine oil, correction coefficient, load

capacity, replacement frequency водства, включающая в себя ТО-1 и ТО-2. Замену масла на двигателях, в соответствии с инструкцией завода-изготовителя, рекомендуется проводить в большинстве случаев при проведении ТО-2 [1]. Периодичность замены масла указывается либо в часах, либо в километрах пробега (заводские нормативы). Заводские нормативы рассчитаны для автомобилей, эксплуатируемых на дорогах с твёрдым покрытием и в климатических условиях центральной России. Корректировку пробегов до ТО-1 и ТО-2 автомобилей в нашей стране при изменении условий эксплуатации рекомендуется проводить согласно действующему положению [2]. При этом учитываются только условия эксплуатации (холмистость местности, дорожные покрытия и интенсивность движения - с помощью коэффициента корректирования $K_{1}$, значения которого лежат в пределах $0,6 \div 1,0$, и природно-климатические условия - с помощью коэффициента корректирования $K_{2}=0,8 \div 1,0$ ).

Таким образом, для самых неблагоприятных условий эксплуатации (дороги, не имеющие твёрдого покрытия $K_{1}=0,6$ и очень холодный климат $\left.K_{2}=0,8\right)$ пробег автомобиля до замены масла будет составлять:

$$
S=S_{0} K_{1} K_{2}=S_{0} 0,8 \times 0,6=0,48 S_{0},
$$

где $S_{0}$ - заводской норматив для замены масла.

Как следует из выражения (1), заводской норматив может быть уменьшен в 2 раза.

В настоящее время ряд зарубежных автомобильных фирм для своей продукции вводят систему периодического ТО. Данный вид ТО имеет нумерацию: ТО-1, ТО-2, ТО-3 ... TO-n, где n-номер ТО перед списанием автомобиля или отправкой его в капитальный ремонт. Замена моторного масла приурочена к проведению периодического ТО. Периодичность зависит как от рекомендаций по конкретным моделям автомобилей, так и от качества применяемых масел и топлива.

В качестве примера приведены рекомендации немецкой фирмы MAN по периодичности замены масла на двигателе седельных тягачей 
серии TGL-DO836, поставляемых в Российскую Федерацию [3]. Грузоподъёмность указанных автомобилей составляет 20 тонн. Данные модели автомобилей комплектуются двигателями серии D0836 (стандарт «Евро-5»), полезная мощность которых составляет 250 кВт (340 л.с). Рекомендуемое масло для двигателей М 3477. Периодичность замены масла в двигателях определяется в зависимости от «тяжести» условий эксплуатации автомобилей, которые оцениваются значениями среднего эксплуатационного расхода топлива, как показано в таблице 1.

Кроме того, приводятся поправочные коэффициенты на указанную периодичность в таблице 1, учитывающие качество применяемого дизельного топлива (содержание серы в нём) и климатические условия, в которых эксплуатируется автомобиль.

Таблица 1 - Зависимость периодичности замены масла в двигателях от эксплуатационных условий

\begin{tabular}{|l|c|c|c|}
\hline \multirow{2}{*}{\multicolumn{1}{|c|}{ Показатель }} & \multicolumn{3}{|c|}{ Условия эксплуатации } \\
\cline { 2 - 4 } & щадящие & средние & тяжёлые \\
\hline Расход топлива, л/100 км & менее 23 & $23-33$ & Более 33 \\
\hline Пробег до замены масла, км & 60000 & 42000 & 24000 \\
\hline
\end{tabular}

Поправочные коэффициенты для топлива приведены в таблице 2.

Поправочный коэффициент, учитывающий климатические условия, рекомендуется вводить следующим образом (применительно к нашей стране): если средняя температура атмосферного воздуха ниже $-20^{\circ} \mathrm{C}$ более трёх месяцев в году, то величины пробегов до замены масла, указанные в таблице 1, следует умножить на коэффициент 0,7 .

Таким образом, если при эксплуатации автомобилей MAN в благоприятных условиях эксплуатации периодичность замены масла равна 60000 км, то для самых неблагоприятных условий

Таблица 2 - Поправочные коэффициенты на пробег автомобиля до замены масла с учётом качества топлива

\begin{tabular}{|c|c|}
\hline Содержание серы (S) в дизельном топливе, мг/кг & $\begin{array}{c}\text { Поправочный коэффициент на пробег автомобиля } \\
\text { до замены масла }\end{array}$ \\
\hline Менее 50 & 1,0 \\
\hline $50<\mathrm{S}<1000$ & 0,5 \\
\hline Более 1000 & 0,3 \\
\hline
\end{tabular}

и низком качестве топлива она будет составлять: 24000 км × 0,7 x 0,3=5040 км, т.е. уменьшается примерно в 12 раз.

Существенное увеличение периодичности замены масла имеет место на серийных двигателях семейства ЯМ3-530 (4- и 6-цилиндровые с рабочим объёмом 4,34 и 6,65 л), производство которых освоено в Ярославском ПАО «Автодизель». Двигатели имеют размерность: диаметр цилиндра $D=105$ мм и ход поршня $S=128$ мм. Мощность двигателей ЯМ3-534 и ЯМ3-536, а также их модификаций - от 90 кВт (120 л.с.) до 235 кВт (320 л.с.). Указанные двигатели являются рядными.

Так, в руководстве по эксплуатации двигателей ЯМ3-536 определено, что замену масла необходимо проводить через каждые 30000 км пробега для автосамосвалов и автобусов, рабо- тающих на городских маршрутах, и через 50000 км - для автомобилей и автобусов, работающих на междугородних перевозках соответственно грузов и пассажиров [4].

В процессе эксплуатации автомобилей бесспорно необходимо выдерживать нормы по периодичности замены масла в двигателях, рекомендованные заводами-изготовителями автотранспортных средств. Однако для замены масла на двигателях автомобилей и тракторов, работающих в конкретных условиях эксплуатации, наибольшее значение, наряду с пробегом в километрах или наработкой в часах, имеет объём сжигаемого топлива, при котором мощность и топливно-экономические показатели двигателей, а также изнашивание их деталей, будут находиться в допустимых приделах, обеспечивая ресурс, 
гарантируемый заводами-изготовителями. Для определения указанного объёма необходимо проведение на заводах-изготовителях широкого комплекса эксплуатационных испытаний, направленных на контроль состояния моторного масла, которое характеризуется его физико-химическими показателями (вязкость, диспергирующие свойства, содержание воды в масле, щёлочность, содержание нерастворимых осадков и др.). Работоспособность масла, как правило, ограничивается одним из указанных показателей. Так, эксплуатационными испытаниями, выполненными в своё время под наблюдением инженеров-исследователей экспериментального цеха Ярославского моторного завода, входящего в ПАО «Автодизель», было установлено, что на двигателях ЯМЗ размерности 140/130 мм, работающих в составе седельных тягачей МАЗ грузоподъёмностью 20 т на междугородних перевозках грузов, работоспособность моторного масла ограничивается содержанием в нём нерастворимых осадков. Предельное значение их составляет 1,5\% от общего веса масла. При достижении этого значения необходима замена масла. Дальнейшая эксплуатация двигателя с переработкой масла приведёт к интенсивному износу его деталей и возможному провороту вкладышей в расточках шатунов и блока цилиндров (коренные и шатунные). Такие частицы, проходя с маслом через зазоры в подшипниках, оставляют царапины на слое свинцовистой бронзы вкладышей. Эти цара-

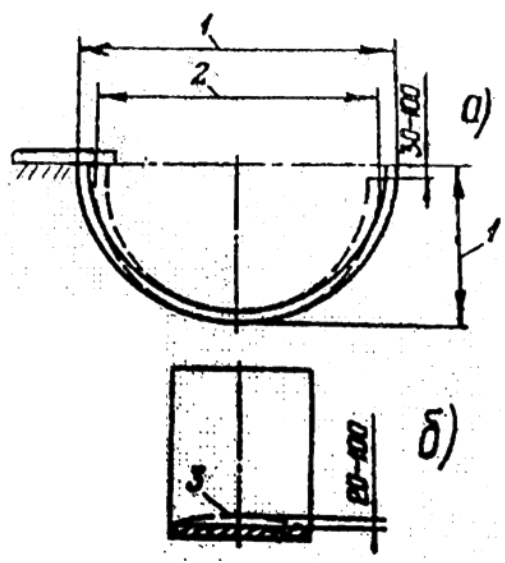

1 - свободные (по чертежу) размеры вкладыша;

2 - размеры после работы вкладыша;

3 - прогиб образующей вкладыша

(размеры указаны в мкм).

Рисунок 1 - Изменение размеров вкладыша при повреждении антифрикционного слоя пины приводят к вспучиванию поверхности вкладышей. Температура вкладышей в месте царапин по замерам, выполненным в ПАО «Автодизель», достигает $400-500^{\circ} \mathrm{C}$ в отдельных случаях $-600^{\circ} \mathrm{C}$.

В результате нагрева происходит тепловое расширение стального основания вкладышей. Ввиду большого натяга вкладышей в расточках шатуна и блока, а также высокой относительной жёсткости постелей под них, увеличение длины вкладышей невозможно, поэтому тепловое расширение вкладышей компенсируется смятием стыков между ними, что приводит к уменьшению размеров и снижению натяга (рис. 1a). Кроме того, вкладыши деформируются и по ширине. Средняя часть вкладышей вспучивается, при этом их выпуклая часть кривой всегда обращена к шейкам коленчатого вала (рис. 16). Вспучивание приводит к ухудшению теплоотвода от вкладышей и их прижиму к постелям в момент приложения нагрузки, а после снятия её за счёт упругих свойств, вкладыши возвращаются в исходное состояние. Слой свинцовистой бронзы в этих условиях подвергается разрушениям. На нём появляются трещины. Период разрушения вкладышей зависит от степени повреждения твёрдыми частицами. «Проворот» вкладышей приводит к выходу из строя целого ряда деталей, среди которых дорогостоящие: коленчатый вал и блок цилиндров. Причины проворота вкладышей в эксплуатации подробно рассмотрены в работе [5].

Учитывая вышеизложенное, необходимо при ремонте двигателей ЯМЗ и КаМАЗ тщательно рассматривать состояние рабочих поверхностей вкладышей. Обращать внимание на наличие выкрашивания рабочего слоя и кольцевых рисок на нём. Такие вкладыши подлежат замене на новые.

Отметим, что с целью своевременной замены масла по объёму расхода топлива, не наносящему вред двигателю, можно его значение выводить на щиток приборов в кабине водителя или сигнал о необходимости замены масла, что возможно сделать при современном уровне развития электроники.

Анализируя данные таблицы 1, можно отметить, что классификация условий эксплуатации по среднему эксплуатационному расходу топлива наиболее эффективна. Так, в тягачах MAN, «щадящие» условия эксплуатации характеризуются расходом топлива 23 л/100 км (замену масла рекомендуется проводить при достижении пробега 60000 км). Следовательно, замена масла производится после объёма сожжённого топлива 23 х $60000 \times 10^{-2}=13800$ л. Аналогичная картина при 
средних условиях эксплуатации $33 \times 42000 \times 10^{-2}$ $=13860$ л, т.е. объём топлива тот же самый, что и при «щадящих» условиях эксплуатации. Верхний предел эксплуатационного расхода топлива для тяжёлых условий эксплуатации не указан, поэтому определить предельные значения объёма сжигаемого топлива невозможно.

Если бы замена масла на автомобилях MAN производилась для «щадящих» и средних условий эксплуатации по объёму сжигаемого топлива, то при фактических расходах топлива соответствен- но менее 23 и 33 л/100 км, пробег автомобилей был бы больше указанных значений в таблице 1. Это позволило бы предприятиям, эксплуатирующим автомобили MAN, снизить расходы на моторное масло.

Приведённые в статье данные по периодичности замены моторного масла на дизельных автомобилях, по мнению авторов, представляют интерес для инженерно-технических работников, занятых в сфере эксплуатации автомобильного транспорта.

\section{תumepamypa}

1. Силовые агрегаты. Руководство по эксплуатации. 236НЭ-3902150 РЭ [Текст]. - Ярославль: ПАО «Автодизель», 2008. - 392 с.

2. Положение о техническом обслуживании и ремонте подвижного состава автомобильного транспорта [Текст]. - М.: Транспорт, 1986. - 72 с.

3. MAN Workshop Infosystem (MAN WIS). Руководство по техническому обслуживанию и эксплуатационным материалам [Текст]. - 2005.

4. Руководство по эксплуатации двигателей ЯМЗ-536 и их модификаций (Руководство по эксплуатации 536.3902150 РЭ) [Текст]. - Ярославль: ПАО «Автодизель», 2013. - 240 с.

5. Антропов, Б.С. Диагностирование автотранспортных средств [Текст] / Б.С. Антропов, И.С. Басалов. Ярославль: Изд. ЯГТУ, 2016. - 144 с.

\section{References}

1. Silovye agregaty. Rukovodstvo po ekspluatacii. 236NE-3902150 RE [Tekst]. - Yaroslavl': PAO «Avtodizel'», 2008. - $392 \mathrm{~s}$.

2. Polozhenie o tekhnicheskom obsluzhivanii i remonte podvizhnogo sostava avtomobil'nogo transporta [Tekst]. - M.: Transport, 1986. $-72 \mathrm{~s}$.

3. MAN Workshop Infosystem (MAN WIS). Rukovodstvo po tekhnicheskomu obsluzhivaniyu i ekspluatacionnym materialam [Tekst]. - 2005.

4. Rukovodstvo po ekspluatacii dvigatelej YaMZ-536 i in modifikacij (Rukovodstvo po ekspluatacii 536.3902150 RE) [Tekst]. - Yaroslavl': PAO «Avtodizel'», 2013. - 240 s.

5. Antropov, B.S. Diagnostirovanie avtotransportnyh sredstv [Tekst] / B.S. Antropov, I.S. Basalov. - Yaroslavl': Izd. YaGTU, 2016. - 144 s. 